\title{
"Experiências em Relações Próximas", um questionário de avaliação das dimensões básicas dos estilos de vinculação nos adultos: Tradução e validação para a população Portuguesa
}

\author{
João M. Moreira \\ Wolfgang Lind \\ Maria João Santos \\ Ana R. Moreira \\ Mário Jorge Gomes \\ João Justo \\ Ana Paula Oliveira \\ Luís André Filipe \\ Mário Faustino \\ Universidade de Lisboa, Portugal
}

\section{Resumo}

Este artigo apresenta o desenvolvimento do questionário "Experiências em Relações Próximas", versão Portuguesa do "Experiences in Close Relationships" (Brennan, Clark, \& Shaver, 1998), bem como dados relativos à sua precisão e validade. Este questionário pretende avaliar as duas dimensões básicas das diferenças individuais no estilo de vinculação dos adultos, a evitação e a preocupação, as quais emergiram da análise factorial de um conjunto abrangente de itens em uso corrente na avaliação da vinculação nos adultos. Os dados relativos à versão Portuguesa mostram que, embora se verifiquem alguns problemas no ajustamento dos dados ao modelo de medida pressuposto, os resultados revelam elevados níveis de precisão por consistência interna e relações significativas com outras variáveis, tal como seria de prever a partir da teoria da vinculação. Estas variáveis incluem não só medidas de auto-relato, como também variáveis de outros tipos, mostrando que as correlações encontradas não correspondem apenas a factores de método.

A correspondência relativa a este artigo deverá ser enviada para: João Manuel Moreira, Faculdade de Psicologia e de Ciências da Educação, Universidade de Lisboa, Alameda da Universidade, 1649-013 Lisboa, Portugal; Tel.: +351217943863; Fax: +351217933408; E-mail: jmoreira@fpce.ul.pt 
Palavras-chave: Estilo de vinculação nos adultos, Evitação, Experiências em relações próximas, Preocupação, Questionário.

\begin{abstract}
This article presents the development of the "Experiências em Relações Próximas" questionnaire, the Portuguese version of "Experiences in Close Relationships" (Brennan, Clark, \& Shaver, 1998), together with data concerning its reliability and validity. This questionnaire intends to assess the two basic dimensions of individual differences in adult attachment style, namely avoidance and preoccupation, which have emerged from the factor analysis of a comprehensive set of items in current use for the assessment of adult attachment. Data obtained with the Portuguese version show that, while some problems were met regarding their adjustment to the predicted measurement model, scores show high levels of internal consistency reliability and significant relations with other variables, as would be predicted by attachment theory. These variables were not only of the self-report type, but included other types of measures, showing that the correlations found were not merely due to method factors.
\end{abstract}

Key words: Adult attachment style, Avoidance, Experiences in close relationships, Concern, Questionnaire.

A teoria da vinculação, elaborada nos seus princípios fundamentais pelo psiquiatra Inglês John Bowlby (1958/1976, 1969, 1973, 1979, 1980, 1988; Cassidy \& Shaver, 1999), postula a existência de um sistema inato de auto-regulação do comportamento (o sistema de vinculação) que, através de um mecanismo de feedback negativo, persegue o objectivo de manter a proximidade de uma figura protectora e de confiança. Embora seja evidente que este sistema tem um grau máximo de influência sobre o comportamento durante os primeiros anos de vida, Bowlby (1979, p. 129) afirmou desde muito cedo que "o comportamento de vinculação caracteriza o ser humano desde o berço até à sepultura".

Mas, mais ainda do que estes mecanismos supostamente universais na espécie humana, têm sido as diferenças individuais no comportamento (e aspectos conexos) de vinculação a dar origem ao maior número de investigações, sobretudo na sequência do contributo de Mary Ainsworth. Esta autora concebeu, juntamente com um conjunto de colaboradores (Ainsworth, Blehar, Waters, \& Wall, 1978), um procedimento padronizado aplicável a crianças entre 12 e 18 meses de idade, sujeitas a breves separações da mãe, num local desconhecido e na presença de uma pessoa estranha. Através do comportamento observado no momento da reunião com a mãe, foi possível distinguir entre diferentes "estilos de vinculação": (a) crianças "seguras", que procuravam o contacto com a mãe na reunião e rapidamente reduziam as suas manifestações de perturbação em resposta a esse contacto, retomando a exploração do meio; (b) crianças "evitantes", que se mostravam pouco perturbadas com a separação e, na reunião, ignoravam a mãe ou evitavam activamente o contacto com ela; (c) crianças "ansiosas/ambivalentes", que se mostravam muito ansiosas e dependentes da mãe durante todo o procedimento, entravam em desespero durante as separações e, aquando das reuniões, mostravam ou uma atitude passiva ou uma procura intensa de contacto, misturada com manifestações de raiva e mesmo de agressividade dirigidas à mãe. A validade desta classificação e do procedimento que a permitiu foi apoiada no mesmo estudo por observações das díades realizadas em casa, bem como por numerosos estudos posteriores (ver Weinfield, Sroufe, Egeland, \& Carlson, 1999). 
Este sistema de classificação esteve na base da maioria das investigações desde então realizadas sobre a vinculação, quer na infância, quer na idade adulta. Dentro desta última, surgiram duas grandes correntes. Uma delas, protagonizada por colaboradores directos de Ainsworth, utiliza quase exclusivamente técnicas de entrevista (Hesse, 1999). A outra, protagonizada por investigadores oriundos da psicologia social, utiliza predominantemente questionários de auto-descrição. Os instrumentos construídos dentro de uma e de outra não parecem correlacionar-se senão a um nível fraco, permitindo levantar dúvidas sobre se medem de facto os mesmos construtos (Crowell, Treboux, \& Waters, 1999).

No estudo inaugural desta segunda corrente, publicado em 1987 por Hazan e Shaver, o estilo de vinculação dos adultos foi avaliado por uma técnica de escolha forçada com um único item. Os autores desenvolveram, extrapolando a partir da teoria e da literatura empírica sobre a vinculação na infância, três parágrafos que descreviam os comportamentos, sentimentos e ideias que adultos em cada um dos três estilos de vinculação encontrados por Ainsworth deveriam demonstrar nas suas relações de vinculação na idade adulta. Segundo estes autores, seria nas relações românticas ou de casal que mais provavelmente se encontrariam comportamentos de vinculação nos adultos (Shaver, Hazan, \& Bradshaw, 1988). Assim, os participantes eram solicitados a escolher, de entre os três parágrafos, aquele que mais se assemelhasse à sua própria experiência em relações românticas.

Apesar de esta primeira medida de vinculação nos adultos ter sido utilizada em numerosos estudos (tendo inclusive uma versão Portuguesa; J. M. Moreira, Bernardes, Andrez, Aguiar, Moleiro, \& Silva, 1998), as suas limitações eram evidentes. Muitos participantes lamentavam a obrigatoriedade de escolher um e um só parágrafo, afirmando que mais do que um (ou nenhum) se lhes aplicava, ou que consideravam apresentar características intermédias entre deles. Outros afirmavam identificar-se com algumas das características descritas nalgum dos parágrafos, mas não com todas. Para além destes inconvenientes, limitações mais sérias eram apontadas do ponto de vista psicométrico. Primeiro porque resultados obtidos com um único item deveriam apresentar uma baixa precisão ("reliability"), o que foi confirmado por estudos de reteste (Scharfe \& Bartholomew, 1994). Segundo, porque o nível de medida em que se situavam os resultados (nominal), impunha limitações em termos das análises estatísticas admissíveis. Finalmente, porque a escolha dos parágrafos como um todo impedia a avaliação do postulado de que as diversas características apontadas em cada um deles seriam escolhidas de forma consistente pelas mesmas pessoas, bem como do postulado de que os três estilos propostos eram suficientes para a descrição do domínio das diferenças individuais na vinculação nos adultos.

Estes problemas foram em parte ultrapassados nalguns estudos em que se pediu aos participantes que avaliassem o grau em que a sua experiência pessoal se identificava com o que era descrito nos parágrafos, através de escalas de avaliação (e.g., Levy \& Davis, 1988). No entanto, uma solução satisfatória só foi obtida através da segmentação em frases dos parágrafos de Hazan e Shaver, e da transformação de cada uma dessas frases num item, respondido através de uma escala de avaliação independente. Este procedimento permitiu o cálculo de coeficientes de precisão por consistência interna e, mais importante ainda, o emprego da análise factorial exploratória com o intuito de identificar as dimensões das diferenças individuais subjacentes às respostas.

Rapidamente diversos autores começaram a apresentar resultados de análises factoriais realizadas sobre conjuntos de itens derivados dos parágrafos de Hazan e Shaver (1987), por vezes adicionados de novos itens elaborados pelos próprios autores. Assim, Mikulincer, Florian, e Tolmacz (1990) obtiveram três factores a partir de 15 itens derivados destes parágrafos, correspondendo aos três estilos originais. Collins e Read (1990) fizeram o mesmo, juntando mais alguns itens da sua autoria, e encontraram três factores diferentes dos de Mikulincer et al. (1990). Enquanto o factor correspondente ao estilo ansioso/ /ambivalente se mantinha, dois factores algo correlacionados entre si pareciam focalizar diferentes aspectos da distinção seguro vs. evitante: o conforto com a proximidade/intimidade e o conforto com o 
apoio/dependência. Num terceiro estudo de Simpson (1990), apenas dois factores foram encontrados, estabelecendo oposições seguro vs. evitante e ansioso/ambivalente vs. não ansioso/ambivalente. Esta última estrutura era também apoiada pelos resultados dos estudos com escalas de avaliação globais para os parágrafos, nos quais se encontrava geralmente uma nítida correlação negativa entre os resultados para os estilos seguro e evitante, enquanto que o estilo ansioso/ambivalente tendia a não apresentar correlações elevadas com nenhum dos outros dois (e.g., C. Hendrick \& Hendrick, 1989).

No seu conjunto, estes resultados pareciam ser compatíveis com um modelo essencialmente bidimensional para o estilo de vinculação nos adultos. Esta hipótese foi reforçada com o surgimento da proposta teórica de Bartholomew (1990; Bartholomew \& Horowitz, 1991) a qual postulava que, subjacentes a estas duas dimensões, estariam afinal os modelos internos dinâmicos postulados por Bowlby. Deste modo, uma representação positiva tanto de si próprio como do parceiro relacional corresponderia ao estilo seguro e uma representação negativa de si próprio mas positiva do outro caracterizaria o estilo ansioso/ambivalente. Quanto ao estilo evitante, Bartholomew (1990) propôs uma distinção adicional entre um estilo evitante-receoso ("fearful-avoidant") que deseja a proximidade mas a evita porque, ao mesmo tempo, receia as suas consequências, e um estilo evitante-desligado (“dismissive-avoidant") que nega qualquer desejo de proximidade íntima com os outros. Enquanto o primeiro terá uma representação negativa tanto de si como dos outros, o segundo associa uma representação positiva de si próprio a uma representação negativa dos outros. Para uma apresentação das medidas derivadas deste modelo teórico e respectivos estudos de validade, ver Bartholomew e Horowitz (1991) e Griffin e Bartholomew (1994a,b).

Mas o principal estudo na base da preferência de que o modelo bidimensional goza actualmente é o de Brennan et al. (1998). Como atrás dito, a partir do início dos anos 90 diversos autores começaram a apresentar diferentes versões dos itens derivados dos parágrafos de Hazan e Shaver (1987), bem como novos itens da sua própria autoria e mesmo escalas completamente novas, medindo os mesmos construtos ou outros derivados dos trabalhos de Bowlby, Ainsworth e outros autores. Numa tentativa de pôr cobro à proliferação de medidas, Brennan et al. (1998) procederam a uma recolha exaustiva de itens relacionados com a vinculação, obtendo um total de 323, distribuídos por 60 escalas. Uma análise factorial deste corpus (ao nível das escalas) numa amostra de 1086 estudantes universitários produziu dois factores com maior peso e com correlações significativas com todas as escalas, o que foi considerado pelos autores como significando que todos os construtos propostos pelos diferentes autores estariam abrangidos por estas duas dimensões. Os dois factores assim obtidos eram muito semelhantes aos do estudo de Simpson (1990), correspondendo às dimensões de evitação $v s$. conforto com a proximidade e ansiedade/ambivalência vs. ausência de ansiedade/ambivalência ${ }^{1}$.

Com o objectivo de obter um questionário razoavelmente breve mas que permitisse avaliar adequadamente estes dois factores, os autores seleccionaram, de entre a amostra inicial de itens, os 36 que apresentavam correlações mais elevadas, em valor absoluto, com os factores (18 itens para cada factor). Este par de escalas deu origem ao questionário "Experiences in Close Relationships". Que estas duas escalas constituem medidas válidas dos dois factores encontrados, era assegurado pela sua correlação de .95 com os factores respectivos (valor idêntico para ambas as escalas), bem como pela baixa correlação entre si (.11), consistente com o princípio teórico da independência entre as duas dimensões. Coeficientes de precisão por consistência interna ou reteste não foram apresentados neste estudo inicial.

Este questionário tem sido desde então considerado como o questionário de referência para a avaliação das duas dimensões básicas do estilo de vinculação nos adultos, ao que não será também

\footnotetext{
1 Embora Brennan et al. (1998) tenham designado este factor (e a escala correspondente) como de "Ansiedade", optámos por intitulá-lo de "Preocupação" (com as relações), dado o conteúdo de muitos dos seus itens e com o intuito de evitar qualquer confusão com o construto teórico ou psicopatológico de ansiedade. A alternativa de "Ambivalência" seria igualmente inadequada, uma vez que não reflecte o conteúdo dos itens e poderia criar ambiguidades indesejadas com outros construtos (e.g., subescala de Ambivalência da RRF no Estudo 2).
} 
alheia a actual predominância do modelo bifactorial na investigação sobre a vinculação. Este fenómeno de causalidade recíproca tem levado a que este instrumento tenha sido utilizado em numerosas investigações recentes (e.g., Jerome \& Liss, 2005; Mallinckrodt, Porter, \& Kivlighan, 2005; Obegi, Morrison, \& Shaver, 2004) e traduzido em diversas línguas (e.g., Hebraico, por Mikulincer \& Florian, 2000; Francês, por Lafontaine \& Lussier, 2003; Chinês, por Mallinckrodt \& Wang, 2004). Todas estas razões justificavam amplamente a sua tradução e validação numa versão Portuguesa.

Uma vez obtida a versão original em língua Inglesa do questionário e efectuada a respectiva tradução e retroversão, o ERP foi utilizado num conjunto de investigações nas quais se obtiveram os primeiros indicadores quanto às suas qualidades de precisão e validade. Embora essas investigações tivessem abrangido diferentes populações, optámos por conjugar os seus dados num único estudo, por forma a obter uma amostra mais numerosa e que proporcionasse maior confiança nas análises, particularmente no caso da análise factorial. Assim, designámos por sub-amostras 1,2 e 3 as recolhidas nas diferentes investigações, dado que, embora tivessem sido agregadas para a análise factorial e da precisão, os seus resultados quanto a outros aspectos da validade de construto são independentes entre si e serão apresentados em subsecções separadas.

Assim, na sub-amostra 1, foram recolhidos dados acerca da vinculação em mulheres com e sem história de Interrupção Espontânea da Gravidez (IEG) e que estavam ou não grávidas no momento da recolha dos dados. Emborar sem querer entrar aqui em discusões acerca da questão do sentido da causalidade (ver, a propósito, A. R. Moreira, 2001), pareceu-nos teoricamente defensável hipotetizar que uma história de IEG deveria estar associada a um estilo de vinculação mais inseguro (mais evitante e preocupado). Do mesmo modo nos pareceu plausível que a presença de um estdo de gravidez, quer pelas alterações hormonais que acarreta, quer pelo seu significado em termos da criação de uma nova relação de grande intimidade física (Fleming, Ruble, Krieger, \& Wong, 1997), quer pela possibilidade que levanta de ultrapassagem do problema para as mulheres com uma hitória de IEG, tivesse um efeito no sentido oposto, promovendo uma vinculação mais segura.

Na sub-amostra 2, foram recolhidos dados de um grupo de mulheres vítimas de violência doméstica e de um grupo de controlo de mulheres sem vitimização. Aqui, como é natural, esperava-se que a validade de construto do questionário se traduzisse em níveis mais elevados de vinculação insegura no grupo das mulheres vítimas de violência, podendo essa insegurança ser resultado da disfuncionalidade da relação ou, mesmo, constituir um factor predisponente para problemas relacionais capazes de conduzir a situações de violência. Mais particularmente, esperávamos neste caso encontrar resultados mais elevados na escala de Evitação para o grupo de vítimas, uma vez que esta escala, pelo seu sentido de afastamento e receio da intimidade, estará mais provavelmente associada à violência relacional do que a Preocupação, cujo significado está mais ligado à incerteza quanto aos sentimentos de amor por parte do parceiro.

Finalmente, na sub-amostra 3, o estilo de vinculação das mulheres da amostra foi relacionado com os níveis de adaptação à escola demonstrados pelos seus filhos no primeiro ano de escolaridade. Dado aquilo que se sabe acerca da transmissão intergeracional dos estilos de vinculação (van IJzendoorn, 1995) e das dificuldades de adaptação à escola de crianças com estilos de vinculação inseguros (Moss, St-Laurent, Rousseau, Parent, Gosselin, \& Saintonge, 1999) e, ainda, dos pressupostos teóricos acerca do papel que a segurança da vinculação desempenha na adaptação a situações novas, como é o caso da escolaridade para crianças de 6 anos, esperava-se que, caso os resultados do ERP fossem válidos como indicadores do estilo de vinculação das mulheres da amostra, a Evitação e a Preocupação estivessem relacionadas com indicadores menos favoráveis de adaptação à escola nos filhos dessas mulheres. Concretamente, seria de esperar que se encontrassem níveis mais elevados de hiperactividade e de comportamentos de oposição entre os filhos de mães com níveis mais elevados de Evitação, e níveis mais baixos de atenção e de competências sociais em filhos de mães com valores mais elevados de Preocupação. 


\section{Estudo 1}

\section{Método}

\section{Participantes}

Este primeiro estudo empregou uma amostra exclusivamente feminina, tendo sido recolhidos 309 questionários, dos quais 287 completos. A amostra foi recolhida no âmbito de três investigações diferentes. A sub-amostra 1, recolhida no âmbito da investigação para uma tese de mestrado (A. R. Moreira, 2001), consistiu num grupo de 100 mulheres, dividido em quatro grupos de 25, resultando do cruzamento de duas variáveis: (a) presença $v s$. ausência de história de IEG e (b) gravidez ( $2^{\circ}$ trimestre) $v s$. ausência de gravidez no momento da recolha dos dados. Os questionários foram aplicados individualmente, em situação de entrevista. A sub-amostra 2 foi recolhida no âmbito de um trabalho de investigação realizado por estudantes de licenciatura (Oliveira, Filipe, \& Faustino, 2000). Era igualmente composta por 100 mulheres, sendo que 50 destas eram vítimas de violência doméstica, constituindo as outras 50 um grupo de controlo. As respostas de 3 mulheres foram excluídas devido ao facto de os questionários estarem incompletos, o que deixou 49 protocolos válidos no grupo com vitimização e 48 no grupo sem vitimização. A sub-amostra 3, recolhida no âmbito da investigação para uma tese de mestrado (Gomes, 2001), era composta por 90 mulheres, mães de crianças matriculadas, pela primeira vez nesse ano lectivo, em cinco escolas do ensino básico de uma freguesia urbana do concelho de Lisboa.

A média de idades das mulheres era de 34.01 anos, com um desvio-padrão de 8.57. Dados sobre a escolaridade apenas foram recolhidos para as sub-amostras 1 e 3 , indicando $23 \%$ de mulheres com até 4 anos de escolaridade, $19 \%$ com 5 ou 6 anos, $11 \%$ entre 7 e 9 anos, $6 \%$ entre 10 e 12 anos, e $41 \%$ com 13 ou mais anos. Em termos de estado civil, $5 \%$ das mulheres eram solteiras, $68 \%$ casadas, $1 \%$ viúvas, $6 \%$ divorciadas, e $21 \%$ vivendo em união de facto. Quanto ao estatuto relacional, $7 \%$ não tinham na altura um parceiro romântico/sexual, 1\% tinham um parceiro com o qual não coabitavam, e $92 \%$ tinham um parceiro com o qual coabitavam.

\section{Medidas}

Experiências em Relações Próximas. Uma vez recebido o questionário na sua versão em Inglês (Apêndice $\mathrm{A})^{2}$, a tradução foi efectuada pelo primeiro autor deste artigo. Foi obtida uma retroversão independente para Inglês, a qual, comparada com o original, não revelou quaisquer distorções no significado dos itens. Após algumas aplicações-piloto, foi decidido introduzir pequenas modificações de vocabulário e desenvolver versões diferentes para homens (Apêndice B) e mulheres (Apêndice C), de modo a facilitar a tarefa dos respondentes e eliminar protestos ocasionais por parte destes. Para além disso, e com o mesmo intuito, foi decidido modificar a forma de marcação das respostas, utilizando uma escala de avaliação de tipo tradicional colocada à direita de cada item, no lugar da forma original, que apresentava a escala apenas no cimo de cada página e um pequeno espaço para inscrição do número correspondente à resposta à esquerda de cada item. A escala de avaliação manteve os sete pontos da versão original, com apenas os pontos extremos (1 - "Discordo fortemente", 7 - "Concordo fortemente") e o ponto central (4 - "Neutro/Misto") definidos verbalmente. Os 36 itens componentes

1 O questionário objecto deste artigo é a versão original desenvolvida por Brennan et al. (1998). Fraley, Waller, e Brennan (2000) introduziram ligeiras modificações a partir de uma análise baseada na Teoria da Resposta ao Item, mas os ganhos psicométricos obtidos com essas modificações são mínimos (Philip R. Shaver, comunicação pessoal, 25 de Julho de 2004). 
das duas escalas são intercalados de forma sistemática, correspondendo os ímpares à escala de Evitação e os pares à escala de Preocupação.

Para a cotação do questionário, calcula-se a média dos itens que compõem cada uma das escalas, tendo o cuidado de inverter previamente os resultados dos itens que estão formulados no sentido oposto ao da generalidade da escala (i.e., em que uma maior concordância é sinal de níveis mais baixos de Evitação ou Preocupação). Esta inversão implica as seguintes trocas de valores: $1 \rightarrow 7$ (1 passa a contar como 7), $2 \rightarrow 6,3 \rightarrow 5$, 4 mantém-se, $5 \rightarrow 3,6 \rightarrow 2,7 \rightarrow 1$. Os itens a submeter a esta transformação são os indicados pelos números 3, 15, 19, 22, 25, 27, 29, 31, 33 e 35. O questionário está disponível para ser utilizado por outros investigadores, podendo ser encontrado nos apêndices $\mathrm{B}$ e $\mathrm{C}$ deste artigo (versão masculina e feminina, respectivamente). Uma versão em formato A4, num ficheiro Adobe pdf, pronta para impressão e aplicação, pode ser obtida via e-mail junto do primeiro autor deste artigo. Por ser este instrumento o principal foco de interesse do presente artigo, as suas qualidades psicométricas serão abordadas na secção dos resultados.

\section{Procedimento}

Sub-amostra 1. As mulheres foram abordadas em instituições de saúde da área da Grande Lisboa. A aplicação do questionário e a recolha de outros dados foram feitas em formato de entrevista individual.

Sub-amostra 2. As mulheres do grupo com vitimização (vítimas de violência doméstica) foram convidadas a participar após o atendimento por um técnico numa associação dedicada à prestação de apoio a pessoas vitimizadas. As participantes do grupo sem vitimização foram recrutadas na rede social dos estudantes que elaboraram o trabalho. A aplicação foi individual em todos os casos.

Sub-amostra 3. As participantes responderam, em pequenos grupos, na escola frequentada pelos seus filhos, a um pequeno questionário de dados demográficos e ao ERP. Imediatamente antes, responderam à escala ACTeRS (Ullmann, Sleator, Sprague, \& MetriTech Staff, 1997), um questionário que avalia o comportamento escolar das crianças e que foi traduzido e adaptado para a população Portuguesa por Gomes (2001). Este questionário, aplicável tanto aos pais como aos professores das crianças em causa, mede quatro dimensões individualizadas do comportamento na escola: Atenção, Hiperactividade, Competências Sociais e Comportamentos de Oposição. A recolha dos dados foi levada a cabo após as crianças terem frequentado durante um período de um mês a um mês e meio o $1^{\circ}$ ano do $1^{\circ}$ Ciclo do Ensino Básico, antes de ter sido realizada qualquer avaliação formal na escola. Foram inicialmente contactadas por carta um total de 313 mães, mas apenas 109 concordaram em participar. Destas, 19 tiveram os seus dados eliminados por os questionários terem sido preenchidos por outra pessoa que não a mãe da criança, ou por estarem incompletos.

\section{Resultados}

\section{Análise factorial e de consistência interna}

O modelo de medida proposto pelos autores originais para o ERP foi testado através de uma análise factorial exploratória, utilizando a técnica da análise em factores principais e a rotação Varimax padronizada. Os resultados, em termos de saturações dos itens, são apresentados no Quadro 1. É visível que os dois factores intencionalmente extraídos correspondem às duas escalas visadas na construção 
do questionário, sendo que cada um dos itens (ímpares vs. pares) apresenta, sem excepção, a sua saturação mais elevada no factor a que corresponde. Estes resultados demonstram que a estrutura factorial é reproduzida com suficiente estabilidade, ainda que a qualidade do desempenho varie de uns itens para outros, com saturações variáveis no factor pressuposto, e saturações frequentemente não negligenciáveis no outro factor (e.g., itens $4,11,12,26)$.

\section{Quadro 1}

Saturações dos itens do ERP nas análises factoriais

\begin{tabular}{|c|c|c|c|c|c|c|}
\hline \multirow[b]{3}{*}{ Item } & \multirow{2}{*}{\multicolumn{2}{|c|}{$\begin{array}{c}\text { Estudo 1 } \\
\text { Sexo Feminino }\end{array}$}} & \multirow{2}{*}{\multicolumn{2}{|c|}{$\begin{array}{c}\text { Estudo } 2 \\
\text { Sexo Masculino }\end{array}$}} & \multirow{2}{*}{\multicolumn{2}{|c|}{$\begin{array}{c}\text { Estudo } 2 \\
\text { Sexo Feminino }\end{array}$}} \\
\hline & & & & & & \\
\hline & Ev. & Pr. & Ev. & Pr. & Ev. & Pr. \\
\hline 1 & -.65 & .14 & .56 & -.04 & .48 & .11 \\
\hline 2 & -.05 & .44 & -.04 & .46 & -.11 & .57 \\
\hline 3 & .66 & .12 & -.31 & .36 & -.51 & .36 \\
\hline 4 & .28 & .40 & -.43 & .39 & $\begin{array}{l}-.31 \\
-\end{array}$ & .38 \\
\hline 5 & -.68 & .16 & .53 & -.01 & .52 & $\begin{array}{r}-.01 \\
-01\end{array}$ \\
\hline 6 & -.15 & .46 & .09 & .51 & .18 & .39 \\
\hline 7 & -.57 & .09 & .46 & -.01 & .53 & .09 \\
\hline 8 & .24 & .45 & -.11 & .51 & -.15 & .59 \\
\hline 9 & -.66 & .12 & .60 & .00 & .66 & .03 \\
\hline 10 & .10 & .50 & -.18 & .45 & -.21 & .58 \\
\hline 11 & -.42 & .40 & .61 & -.01 & .65 & .20 \\
\hline 12 & -.26 & .57 & .53 & .30 & .50 & .24 \\
\hline 13 & -.68 & .23 & .61 & .07 & .61 & .08 \\
\hline 14 & .03 & .52 & -.04 & .54 & -.19 & .49 \\
\hline 15 & .74 & .06 & -.53 & .38 & -.52 & .28 \\
\hline 16 & -.18 & .35 & .44 & .24 & .39 & .34 \\
\hline 17 & -.72 & .10 & .53 & -.03 & .62 & .12 \\
\hline 18 & -.22 & .56 & .04 & .39 & .02 & .50 \\
\hline 19 & .61 & -.14 & -.38 & .20 & -.56 & .06 \\
\hline 20 & -.11 & .48 & .32 & .41 & .31 & .41 \\
\hline 21 & -.51 & .20 & .61 & .11 & .55 & .07 \\
\hline 22 & -.05 & -.42 & .03 & -.30 & .07 & -.44 \\
\hline 23 & -.69 & .04 & .67 & -.06 & .52 & -.21 \\
\hline 24 & .07 & .71 & .15 & .49 & .16 & .49 \\
\hline 25 & .68 & .07 & -.54 & .24 & -.63 & .20 \\
\hline 26 & -.43 & .47 & .58 & .09 & .61 & .26 \\
\hline 27 & .71 & .03 & -.65 & .29 & -.69 & .24 \\
\hline 28 & -.13 & .56 & .22 & .55 & .19 & .52 \\
\hline 29 & .69 & .18 & -.31 & .50 & -.44 & .49 \\
\hline 30 & .17 & .67 & -.03 & .56 & -.05 & .58 \\
\hline 31 & .81 & .11 & -.43 & .44 & -.59 & .43 \\
\hline 32 & $\begin{array}{l}.01 \\
.00\end{array}$ & .57 & .00 & .63 & .06 & .69 \\
\hline 33 & .79 & .09 & -.49 & .45 & -.58 & .42 \\
\hline 34 & -.10 & .50 & .11 & .54 & .14 & .57 \\
\hline 35 & .71 & .20 & -.39 & .57 & -.65 & .32 \\
\hline 36 & .18 & .69 & -.11 & .53 & -.03 & .54 \\
\hline
\end{tabular}

Nota. Mascul. - Resultados para o sexo masculino. Femin. - Resultados para o sexo feminino. Ev. - Factor de Evitação. Pr. - Factor de Preocupação.

Os resultados para a consistência interna mostraram-se também bastante adequados, com valores do coeficiente alfa de Cronbach de .93 para a escala de Evitação e .87 para a escala de Preocupação. Nenhum item faz diminuir o valor do alfa, com excepção do item 11 na escala de Evitação, e mesmo aí de forma muito marginal (de .935 para .934). A correlação, bastante respeitável, deste item com o total (.42) não aconselha a sua eliminação, embora o seu conteúdo deva ser objecto de atenção em futuras revisões.

Um aspecto menos favorável é o da correlação entre as escalas, cujo valor, embora bastante baixo (-.12) atinge a significância num teste bilateral $(p=.045)$. Na origem deste resultado estão concerteza os 
itens que apresentam em simultâneo saturações nos dois factores. Este correlação não deverá, no entanto, constituir problema na maioria das aplicações, nem afectar de forma sensível os dados de validade.

\section{Análise de correlações com outras medidas}

Sub-amostra 1. Verificou-se neste estudo, tal como havia sido inicialmente previsto, que as mulheres com uma história anterior de IEG apresentavam níveis médios mais elevados de vinculação evitante, quando comparados com os da amostra de mulheres sem história de IEG. Uma análise mais detalhada, no entanto, mostrou que esta diferença ocorre apenas entre as mulheres que não se encontram, no momento, em estado de gravidez. Assim, o nível de Evitação revelou-se particularmente elevado entre as mulheres com antecedentes de IEG e que não se encontravam grávidas (ver Quadro 2), sendo claramente mais baixo e muito semelhante em todos os outros grupos. Este padrão dos valores médios reflecte-se também no resultado da análise de variância, que aponta um efeito significativo da presença de história de IEG, $F(1,96)=4.68, p=.03$ e do estado de gravidez, $F(1,96)=3.98, p=.05$ e um efeito muito próximo da significância para a interacção entre estas duas variáveis, $F(1,96)=3.38, p=.07$. Testes de comparações múltiplas (Tukey HSD) confirmaram esta interpretação, mostrando que o grupo de não grávidas com história de IEG se diferenciava significativamente dos outros grupos, cujas diferenças entre si não eram significativas.

\section{Quadro 2}

Médias e desvios-padrão das escalas do ERP, em função da presença de história de IEG e estado de gravidez (Subamostra 1 do Estudo 1)

\begin{tabular}{|c|c|c|c|c|}
\hline & \multicolumn{2}{|c|}{ Evitação } & \multicolumn{2}{|c|}{ Preocupação } \\
\hline & Grávidas & Não Grávidas & Grávidas & Não Grávidas \\
\hline $\mathrm{C} / \mathrm{IEG}$ & $1.99 / 0.84$ & $2.70 / 1.19$ & $4.28 / 0.96$ & $4.71 / 0.98$ \\
\hline $\mathrm{S} / \mathrm{IEG}$ & 1.93 / 0.89 & $1.96 / 0.70$ & $4.20 / 1.03$ & $3.95 / 0.92$ \\
\hline
\end{tabular}

Nota. Média / Desvio-Padrão. C/ IEG - com história de interrupção espontânea da gravidez. S/ IEG - sem história de interrupção espontânea da gravidez.

Um padrão semelhante de resultados foi encontrado para a escala de Preocupação, com um efeito significativo da história de IEG, $F(1,96)=4.71, p=.03$, um efeito não significativo da gravidez, $F(1,96)=0.20, p=.65$, e um efeito de interacção que se aproxima da significância, $F(1,96)=3.06, p=.08$. Neste caso, os testes de comparações múltiplas apenas detectaram uma diferença significativa entre os dois grupos de mulheres não grávidas (com e sem história de IEG), mostrando mais uma vez como o estado de gravidez leva a que se esbata o efeito dos antecedentes de IEG sobre a vinculação insegura. Com uma amostra mais numerosa, este efeito ter-se-ia certamente reflectido numa interacção significativa.

Sub-amostra 2. Os resultados para esta sub-amostra, apresentados no Quadro 3, estão em sintonia com as nossas hipóteses. Os resultados dos dois grupos foram comparados, por opção dos autores do estudo, através de testes não paramétricos de Mann-Whitney, os quais revelaram uma diferença significativa, $W=1566.50, z=.61, p<.01$ para a escala de Evitação e uma diferença não significativa, $W=2376.00, z=1.03, p<.30$ para a escala de Preocupação, embora também no caso desta a diferença vá no sentido esperado, ou seja, de um nível mais elevado de vinculação ansiosa/ambivalente no grupo de mulheres vítimas de violência doméstica. De novo, portanto, os resultados são positivos quanto à validade do ERP. 
Quadro 3

Médias e desvios-padrão das escalas do ERP, em função da presença de violência doméstica (Subamostra 2 do Estudo 1)

\begin{tabular}{lcc}
\hline & Evitação & Preocupação \\
\hline VVD & $4.46 / 1.25$ & $4.70 / 1.25$ \\
N/VVD & $2.52 / 0.98$ & $4.35 / 1.27$ \\
\hline
\end{tabular}

Nota. Média / Desvio-Padrão. VVD - Vítimas de violência doméstica. N/ VVD - Não vítimas de violência doméstica.

Sub-amostra 3. Os resultados para esta sub-amostra, apresentados no Quadro 4 em termos de correlações de Pearson entre as escalas do ACTeRS e do ERP, são bastante positivos em termos da sua validade. Para começar, note-se como os sinais das 16 correlações obtidas vão, sem excepção, no sentido esperado. Resultados indicativos de vinculações mais inseguras por parte das mães (aos seus parceiros igualmente adultos, não esqueçamos) no ERP estão sempre relacionados com tendências no sentido de menor Atenção e Competências Sociais, e de maior Hiperactividade e Comportamentos de Oposição por parte dos seus filhos no início da escolaridade. Mais especificamente, verifica-se uma correlação positiva entre a Evitação (e a Preocupação) das mães e a Hiperactividade das crianças, embora tal só se manifeste quando a avaliação desta última é feita também pelas mães. De modo semelhante, a correlação negativa entre a Preocupação e a Atenção apenas se manifesta na avaliação dos professores. A correlação positiva entre a Evitação e os Comportamentos de Oposição manifesta-se em ambos os casos, ainda que não atingindo a significância. Esta diferenciação dos resultados obtidos com diferentes informadores está longe de ser rara em estudos deste tipo, sendo sabido que aqueles podem fornecer dados que se completam mutuamente. O padrão de correlações encontrado será objecto de uma análise mais detalhada na discussão.

Quadro 4

Correlações entre as escalas do ERP e do ACTeRS (Subamostra 3 do Estudo 1)

\begin{tabular}{lccccc}
\hline & \multicolumn{2}{c}{ Evitação } & & \multicolumn{2}{c}{ Preocupação } \\
\cline { 2 - 3 } \cline { 5 - 6 } Escalas do ACTeRS & Professores & Mães & -.05 & Professores & Mães \\
\hline Atenção & -.13 & $.27^{*}$ & $-.25^{*}$ & -.09 \\
Hiperactividade & .04 & .08 & .15 & .04 & $.19^{*}$ \\
Competências Sociais & .12 & & $.29^{*}$ & $-.26^{*}$ \\
Comportamentos de Oposição & & &
\end{tabular}

Nota. ${ }^{*}$ - significativo para $p<.05$.

Assim, no seu conjunto, os resultados encontrados indicam que as escalas do ERP, para além de apresentarem uma adequada validade discriminante, demonstram também possuir validade de construto, pois as correlações encontradas correspondem àquilo que poderia ser deduzido da teoria da vinculação.

\section{Discussão}

Em termos gerais, os resultados deste primeiro estudo são bastante positivos quanto às qualidades psicométricas do ERP como medida do estilo de vinculação romântica nos adultos. As análises internas ao questionário mostram que os itens constituem bons indicadores dos construtos que se pretende medir, que os dois factores se encontram bem individualizados, que a estrutura factorial é claramente replicável numa análise exploratória, e que ambas as escalas fornecem resultados com uma elevada consistência interna. 
Quanto aos resultados obtidos por correlação com outros instrumentos, as conclusões são também muito favoráveis, revelando que o ERP é sensível às variações ou diferenças individuais na qualidade, proximidade, segurança e significado das relações, indicadas por variáveis que não dependem, na sua maior parte, do auto-relato. Esta independência, não muito comum em estudos com instrumentos deste tipo, permite afastar a possibilidade de correlações triviais devidas a factores de método, um problema recorrente quando os dados de validade se apoiam excessivamente em correlações com outros questionários. Tal não significa que correlações desse tipo não sejam importantes e úteis, sobretudo quando se procuram relações com outros construtos de natureza subjectiva, ou quando se pretende recolher dados sobre um conjunto mais amplo de outras variáveis, como no segundo estudo incluído neste artigo.

Importa também destacar como os padrões de correlações encontradas apoiam a validade discriminante das escalas do ERP. Assim, por exemplo, na sub-amostra 1, o estado de gravidez está relacionado com uma diminuição de Evitação, mas não da Preocupação. Considerando que, na gravidez, existe uma intimidade física quase total entre a mãe e o feto, e que um dos aspectos centrais da evitação é justamente o desconforto com a proximidade e a intimidade, o efeito encontrado faz todo o sentido. Recordemos, por exemplo, como a utilização de dispositivos de transporte dos bebés que implicam um contacto físico íntimo se mostra capaz de promover uma maior sensibilidade aos bebés por parte das mães e uma vinculação mais segura por parte destes (Anisfeld, Casper, Nozyee, \& Cunningham, 1990). A dessensibilização ao carácter aversivo que as mulheres evitantes encontram no contacto íntimo será provavelmente um dos mecanismos deste efeito, o que seria consonante com os nossos resultados. Uma redução da Preocupação, por outro lado, exigiria o desenvolvimento de uma maior confiança na responsividade contingente de um parceiro íntimo, algo que um estado de gravidez não pode facilmente proporcionar.

Quanto à sub-amostra 2, já foi apontado como a presença de um efeito significativo para a Evitação mas não para a Preocupação vai ao encontro das nossas hipóteses. No caso da sub-amostra 3, o padrão de resultados encontrado pode ser interpretado se considerarmos a dinâmica proposta para o funcionamento psicológico do estilo evitante (Main \& Weston, 1982). Devido às atitudes de rejeição por parte das figuras de vinculação, a criança vê-se na necessidade de inibir os seus comportamentos de procura de conforto e de contacto com estas. Como forma de melhor conseguir assegurar essa inibição, a criança explora intensamente o seu ambiente, em especial quando a figura de vinculação está presente, o que explica a hiperactividade reportada pelas mães. Quando a mãe não está presente, no entanto (ou seja, na escola), esta inibição deixa de ser necessária, pelo que a hiperactividade pode não se manifestar tanto. Por outro lado, a ausência de uma base segura internalizada impede que a criança ansiosa/ambivalente se concentre na exploração do seu ambiente, o que explica as avaliações de défices de atenção por parte dos professores, bem como os défices de competências sociais encontrados entre os filhos das mães com resultados elevados na escala de Preocupação do ERP. A incapacidade destas crianças para se sentirem seguras, mesmo na presença da mãe, assim como os comportamentos de oposição que muitas vezes se verificam em relação a esta, podem também ajudar a explicar a correlação significativa algo inesperada entre o resultado das mães na escala de Preocupação e os comportamentos de hiperactividade que atribuem aos seus filhos.

\section{Estudo 2}

Os objectivos deste segundo estudo foram os de alargar a população de recolha de dados para além do sexo feminino empregue no primeiro estudo e de possibilitar o estabelecimento de relações entre os 
resultados do ERP e os de diversos outros questionários, que avaliavam variáveis pertinentes para a verificação da sua validade. $O$ facto de se tratar de instrumentos de auto-relato contribuiu também para completar os resultados obtidos no estudo anterior. Além disso, os dados para este estudo foram recolhidos junto de uma amostra de casais heterossexuais em coabitação, o que permitiu relacionar os resultados do ERP não apenas com os dos questionários preenchidos pela mesma pessoa, mas também com os preenchidos pelo seu parceiro relacional. É sabido não só que existem efeitos do estilo de vinculação sobre aspectos das relações, particularmente das mais íntimas, como também que os estilos de vinculação dos parceiros relacionais não são independentes.

\section{Método}

\section{Participantes}

A amostra para este segundo estudo foi composta por um total de 264 casais heterossexuais em coabitação. No entanto, devido a respostas omissas ou inválidas, apenas ficaram disponíveis 234 questionários ERP completos preenchidos por homens e 218 preenchidos por mulheres. Apenas em 194 casos o ERP foi completa e correctamente preenchido por ambos os membros do casal. O número de casos disponíveis para relações com os resultados de outros instrumentos varia também um pouco devido à presença de respostas inutilizáveis nesses questionários.

A maioria da amostra foi recolhida por intermédio de estudantes voluntários do primeiro ano da licenciatura em Psicologia da FPCE-UL, que obtiveram a colaboração de casais da sua rede social, em troca de crédito numa disciplina do curso. Alguns casos adicionais foram recolhidos na rede social dos autores do estudo (João Moreira, Wolfgang Lind, \& Maria João Santos). Os casais receberam os questionários em envelopes separados e foram instruídos no sentido de os preencherem de forma independente e não os mostrarem ao parceiro, devolvendo-os igualmente em separado, dentro de envelopes fechados. Por isso, acontece que, em alguns casos, as informações, mesmo sobre dados objectivos, fornecidas pelos dois elementos do casal não coincidem. Por exemplo, a duração da coabitação relatada pelos dois parceiros apenas correlaciona .983.

Os casais participantes coabitavam, em média, há cerca de 17 anos (16 anos e 11 meses segundo a informação prestada pelos homens, 17 anos e 2 meses de acordo com as mulheres), com um desvio-padrão de 10 anos e 8 meses, um mínimo de 1 mês e um máximo de 51 anos. Cerca de $69 \%$ dos participantes declararam-se casados religiosamente, $21 \%$ casados apenas civilmente e $10 \%$ não legalmente casados. A média de idades era de 44.21 anos para os homens (desvio-padrão 11.03, amplitude 18-78) e de 42.25 para as mulheres (desvio-padrão 10.32, amplitude 19-77). Em termos de níveis de escolaridade, os valores eram muito semelhantes para homens e mulheres, rondando os $12 \%$ com o $1^{\circ}$ Ciclo do Ensino Básico, $9 \%$ com o $2^{\circ}$ Ciclo, $16 \%$ com o $3^{\circ}$ Ciclo, $27 \%$ com o Ensino Secundário e 35\% com um Curso Superior. O grau de religiosidade foi avaliado através de um item único com uma escala de 1 ("Nada religioso") a 7 ("Extremamente religioso"), que forneceu um valor médio de 3.59 (desvio-padrão 1.48) para os homens e 4.05 (desvio-padrão 1.22) para as mulheres.

\section{Medidas}

Experiências em Relações Próximas. O ERP foi empregue na mesma versão descrita a propósito do Estudo 1, apenas com a diferença de ter sido utilizada, para além da versão redigida para o sexo feminino, também a do sexo masculino. 
Inventário da Qualidade das Relações. Este questionário constitui a versão Portuguesa do Quality of Relationships Inventory (QRI), um questionário que pretende avaliar as qualidades percebidas pelos participantes em relações pessoais específicas (Pierce, Sarason, Sarason, Solky-Butzel, \& Nagle, 1997). Mais concretamente, são avaliadas a percepção de ter Apoio social disponível vindo dessa relação (7 itens; exemplo de item: "Em que medida poderia contar com esta pessoa para o ajudar com um problema?"), de presença de Conflito na relação (6 itens; exemplo de item: "Com que frequência tem de se esforçar para evitar conflitos com esta pessoa?") e de Profundidade e importância da relação (12 itens; exemplo de item: "Em que medida é esta relação importante na sua vida?"). Cada uma destas três escalas é constituída por quatro itens, respondidos numa escala de quatro pontos, de "Nada" a "Muitíssimo". No presente estudo, os participantes foram instruídos no sentido de responderem ao questionário com referência ao seu cônjuge. A versão Portuguesa deste questionário foi desenvolvida por João Moreira, com um processo de tradução e retroversão, e utilizada pela primeira vez neste estudo. Os valores do coeficiente alfa de Cronbach na presente amostra foram de .82 e .85 (para homens e mulheres, respectivamente) para a escala de Apoio, de .87 e .89 para a escala de Conflito, e de .84 e de .86 para a escala de Profundidade.

Relationship Rating Form. A Relationship Rating Form (RRF) é um questionário que pretende medir 7 características globais e 20 facetas de relações românticas ou de amizade (Davis e Latty-Mann, 1987; Levy e Davis, 1988). É composto por um total de 68 itens, que medem as características globais de Viabilidade (incluindo as facetas de Aceitação/Tolerância, Respeito e Confiança), Intimidade (facetas de Confiar e Compreender), Cuidado (facetas de Dar o Máximo, Defender e Assistência), Paixão (facetas de Fascinação, Exclusividade e Intimidade Sexual), Satisfação (facetas de Sucesso, Prazer, Reciprocidade e Estima), Compromisso (sem facetas), e Conflito/Ambivalência (facetas de Conflito e Ambivalência). Existem ainda facetas isoladas de Manutenção, Coerção e Igualdade, que não fazem parte de nenhuma das características globais. Exemplos de itens são: "Aceita esta pessoa tal como ela é?" (escala de Viabilidade, faceta de Aceitação/Tolerância), "Dá-lhe prazer, só de observar ou olhar para esta pessoa?" (escala de Paixão, faceta de Fascinação) e "Sente-se preso(a) nesta relação?" (escala de Conflito/Ambivalência, faceta de Ambivalência). Para além destes resultados em características globais e facetas, um índice global da qualidade percebida da relação pode ser obtido através da soma de todos os itens. Cada item é respondido numa escala de nove pontos, desde "Nada" até "Completamente ou extremamente". A versão Portuguesa deste questionário foi desenvolvida por Wolfgang Lind, com um processo de tradução e retroversão, e utilizada pela primeira vez neste estudo.

Os valores do coeficiente alfa de Cronbach mostraram-se bastante adequados quer ao nível da escala total (.96 para os homens, .97 para as mulheres), quer ao nível das escalas de características globais, todas acima de .80, se exceptuarmos a escala de Conflito/Ambivalência, que apresentou o valor mais baixo, tanto para os homens (.70) como para as mulheres (.76). Devido ao menor número de itens, os valores para as facetas foram naturalmente mais baixos e mais variáveis, oscilando entre .51 (Ambivalência) e .94 (Sucesso) para os homens, e entre .58 (Manutenção) e .97 (Sucesso) para as mulheres.

Escala de Desiderabilidade Social de Marlowe-Crowne. A Escala de Desiderabilidade Social de Marlowe-Crowne (EMC) é a mais conhecida e utilizada de todas as escalas destinadas a avaliar o grau em que os participantes dão respostas social e culturalmente desejáveis que distorcem a realidade. No presente estudo, foi utilizada uma versão Portuguesa reduzida desta escala, desenvolvida por António Simões (Universidade de Coimbra) e composta por 20 itens. Na presente amostra, o coeficiente alfa de Cronbach foi de .78 para os homens e .74 para as mulheres.

Relationship Assessment Scale. A Relationship Assessment Scale (RAS) é uma escala de sete itens, que pretende constituir uma medida genérica de satisfação nas relações de casal (S. S. Hendrick, 1988; 
S. S. Hendrick, Dicke, \& Hendrick, 1998). A presente versão Portuguesa foi desenvolvida e utilizada anteriormente num trabalho não publicado (Santos, Feijão, \& Mesquita, 2000), onde demonstrou boas qualidades psicométricas. Cada item (exemplo: "De um modo geral, até que ponto está satisfeito/a com a sua relação?") é avaliado numa escala de cinco pontos, em que as descrições dos diferentes níveis variam consoante o conteúdo dos itens (para o exemplo dado, variam de "Muito insatisfeito" a "Muito satisfeito"). O coeficiente alfa de Cronbach na presente amostra foi de .91 para os homens e .93 para as mulheres.

\section{Resultados}

\section{Análise factorial e de consistência interna}

Tal como no estudo anterior, foi empreendida uma análise factorial exploratória, separadamente para homens e mulheres, através do método de análise em componentes principais seguido de uma rotação ortogonal do tipo Varimax. Os resultados, em termos de saturações dos itens nos dois factores extraídos, são apresentados no Quadro 1. Considerando estes valores, verifica-se uma redução na clareza da estrutura factorial por comparação com a do Estudo 1. De facto, enquanto que naquele cada item saturava sempre mais no factor ao qual era suposto pertencer do que no factor alternativo, aqui verificam-se vários casos em que os itens saturam com peso praticamente igual nos dois factores (e.g., itens $3,4,20,31$ e 33) e inclusive casos em que a saturação é maior no factor alternativo (e.g., itens $12,16,26,29$ e 35 , este apenas entre os homens).

É igualmente verdade, no entanto, que estes aspectos não se reflectem de forma muito sensível nos indicadores psicométricos mais tradicionais. Os valores dos coeficientes alfa de Cronbach situam-se em níveis adequados: na escala de Evitação, .88 para os homens e .90 para as mulheres; na escala de Preocupação, .82 para os homens e .84 para as mulheres. As correlações entre as escalas são, inclusive, inferiores às do estudo anterior e não atingem a significância: -.10 para os homens e -.03 para as mulheres.

\section{Validade discriminante}

Começaremos a apresentação dos resultados referentes às relações entre o ERP e as outras medidas referindo-nos às diferenças entre sexos, uma vez que a sua inexistência constitui um pressuposto importante da teoria da vinculação. Estas diferenças foram testadas através de uma Análise de Variância Multivariada (MANOVA) com Medidas Repetidas, dado que os homens e mulheres estavam emparelhados naturalmente em casais, funcionando as duas escalas do ERP como variáveis dependentes. O resultado do teste multivariado não foi significativo, $F(2,193)=1.24, p=.29$, não sendo os testes univariados para as duas escalas, mesmo se considerados, também significativos. Parecem, portanto, não existir diferenças significativas entre os sexos nestas dimensões da vinculação, tal como a teoria prevê. Em termos de estatística descritiva, os resultados encontrados para a escala de Evitação apresentavam, entre os homens, uma média de 2.43 e um desvio-padrão de 0.90 e, entre as mulheres, uma média de 2.27 e um desvio-padrão de 0.94. Quanto à escala de Preocupação, apresentava uma média de 4.32 e um desvio-padrão de 0.87 entre os homens, e uma média de 4.33 e um desvio-padrão de 0.91 entre as mulheres.

Em seguida, importaria verificar se os resultados do ERP não apresentariam correlações excessivamente altas com a Escala de Desiderabilidade Social de Marlowe-Crowne. Estas correlações 
foram muito baixas e não significativas em ambos os casos para os homens (-.05 para a Evitação e -.08 para a Preocupação), bem como para a Evitação entre as mulheres (-.03). No entanto, no caso da Preocupação, surgiu uma correlação considerável entre as mulheres $(-.32, p<.001)$, algo estranho sobretudo se tivermos em conta que as atitudes de preocupação com as relações são algo que não é habitualmente mal visto dentro do papel sexual feminino. Este dado algo preocupante (e intrigante) deveria ser objecto de atenção em estudos futuros.

\section{Validade concorrente}

Considerando agora aquelas variáveis que, de acordo com a teoria e a investigação anterior, deveriam estar relacionadas com o estilo de vinculação nos adultos, começámos por considerar as correlações entre o grau de Evitação e de Preocupação evidenciados pelos dois membros de cada casal. Esta correlação foi significativa em ambos os casos, sendo mais pronunciada para a Evitação (.37) do que para a Preocupação (.19). Estes resultados estão de acordo com as investigações que sugerem um certo grau de semelhança entre os estilos de vinculação dentro dos casais (e.g., Collins \& Read, 1990).

O Quadro 5 apresenta as correlações entre os resultados do ERP e do QRI. Considerando em primeiro lugar os resultados para a escala de Evitação, é possível verificar que estes correspondem às previsões efectuadas, revelando que esta dimensão do estilo de vinculação se encontra fortemente ligada à qualidade percebida das relações, dado que os coeficientes de correlação encontrados vão, sem excepção, no sentido esperado (positivo para o Conflito e negativo para o Apoio e a Profundidade), sendo todos estatisticamente significativos. Pelo contrário, os resultados para a escala de Preocupação são mais fracos e inconsistentes, apenas surgindo relacionados de forma sistemática com níveis mais elevados de Conflito. Esta correlação não deve, aliás, constituir supresa, dada a associação entre esta dimensão da vinculação e as sensações de incerteza e de fraco controlo sobre a relação. Finalmente, é curioso o efeito encontrado para esta dimensão sobre a avaliação de Profundidade/Importância da relação feita pelos homens. Acontece que, enquanto graus mais elevados de Preocupação por parte dos próprios homens estão associados à percepção de uma maior Profundidade da relação, quando a mesma característica é apresentada pelas mulheres, os homens percepcionam menos profundidade na relação. Este efeito relaciona-se com a moderação dos efeitos dos estilos de vinculação pelos papéis de género, já identificada por outros autores (e.g., Collins \& Read, 1990), e que será de novo abordada na secção de discussão.

\section{Quadro 5}

Correlações entre as escalas do ERP e do QRI

\begin{tabular}{|c|c|c|c|c|c|c|c|c|}
\hline \multirow{3}{*}{$\begin{array}{l}\text { Parceiro } \\
\text { Respond. }\end{array}$} & \multicolumn{4}{|c|}{ Evitação } & \multicolumn{4}{|c|}{ Preocupação } \\
\hline & \multicolumn{2}{|c|}{ Marido } & \multicolumn{2}{|c|}{ Mulher } & \multicolumn{2}{|c|}{ Marido } & \multicolumn{2}{|c|}{ Mulher } \\
\hline & Marido & Mulher & Mulher & Marido & Marido & Mulher & Mulher & Marido \\
\hline Apoio & $-.49 * *$ & $-.42 * *$ & $-.64 * *$ & $-.30 * *$ & .02 & .03 & -.09 & -.03 \\
\hline Profundidade & $-.58 * *$ & $-.36 * *$ & $-.67 * *$ & $-.28 * *$ & $.13 *$ & -.03 & .03 & $-.13^{*}$ \\
\hline Conflito & $.44 * *$ & $.33 * *$ & $.48^{* *}$ & $.35 * *$ & $.16^{* *}$ & $.13^{*}$ & $.24 * *$ & $.13^{*}$ \\
\hline
\end{tabular}

Nota. Parceiro - Pessoa que responde ao ERP, escala indicada acima. Respond. - pessoa a quem a variável demográfica à esquerda se refere. ${ }^{*}$ - significativo para $p<.05 . * *-$ significativo para $p<.01$.

O Quadro 6 apresenta as correlações entre os resultados das escalas do ERP e as da RRF. Uma vez que os resultados para as facetas são largamente redundantes com os das características globais, e para reduzir a dimensão dos quadros, optámos por apresentar apenas estes últimos. Mais uma vez, olhando para as colunas referentes à escala de Evitação, verificamos que os resultados corroboram os já 
apresentados para o QRI, ou seja, o nível de Evitação está fortemente relacionado com a má qualidade da relação conjugal. Para além disso, no entanto, outro efeito nos parece digno de menção: o efeito da vinculação evitante do homem sobre a avaliação da relação feita pela mulher é em todos os casos mais forte do que o efeito da Evitação da mulher sobre a avaliação que o homem faz da relação. Embora esta diferença de correlações só atinja a significância para a escala de Cuidado, o seu carácter sistemático aponta de novo para a interacção entre os estilos de vinculação insegura e os papéis de género, já mencionados no parágrafo anterior. Ainda a juntar a isso, temos o efeito da Preocupação sobre a avaliação da relação pelo parceiro, que é, na maioria dos casos, mais forte quando é a mulher, e não o homem, a apresentar essa característica. De novo, trata-se de um resultado que seria previsível a partir da interacção já apontada. De natureza diferente, embora não inesperado face àquilo que se sabe acerca da relação entre o estilo Ansioso/Ambivalente e os estilos de amor romântico, é o efeito encontrado no sentido de este estilo de vinculação entre os homens estar associado a níveis significativamente mais elevados de Paixão relatada pelos próprios. Finalmente, de notar ainda que o estilo Ansioso/Ambivalente parece estar associado ao nível de Conflito nas relações, mais do que a outros aspectos da satisfação, tal como tinha já sido encontrado com o QRI.

Quadro 6

Correlações entre as escalas do ERP e as da RRF e RAS

\begin{tabular}{|c|c|c|c|c|c|c|c|c|}
\hline \multirow{3}{*}{$\begin{array}{l}\text { Parceiro } \\
\text { Respond. }\end{array}$} & \multicolumn{4}{|c|}{ Evitação } & \multicolumn{4}{|c|}{ Preocupação } \\
\hline & \multicolumn{2}{|c|}{ Marido } & \multicolumn{2}{|c|}{ Mulher } & \multicolumn{2}{|c|}{ Marido } & \multicolumn{2}{|c|}{ Mulher } \\
\hline & Marido & Mulher & Mulher & Marido & Marido & Mulher & Mulher & Marido \\
\hline Viabilidade & $-.60 * *$ & $-.38 * *$ & $-.67 * *$ & $-.32 * *$ & -.08 & .00 & $-.15^{*}$ & $-.11 *$ \\
\hline Intimidade & $-.63 * *$ & $-.35 * *$ & $-.62 * *$ & $-.31 * *$ & -.09 & -.02 & $-.11^{*}$ & $-.13^{*}$ \\
\hline Paixão & $-.56 * *$ & $-.37 * *$ & $-.67 * *$ & $-.30 * *$ & $.12 *$ & .07 & -.01 & -.06 \\
\hline Cuidado & $-.59 * *$ & $-.45 * *$ & $-.62 * *$ & $-.31 * *$ & -.01 & .03 & $-.11 *$ & -.02 \\
\hline Satisfação & $-.59 * *$ & $-.43 * *$ & $-.69 * *$ & $-.35 * *$ & .03 & -.01 & $-.15 * *$ & -.10 \\
\hline Confl./Amb. & $.45 * *$ & $.33 * *$ & $.50 * *$ & $.21 * *$ & $.13 *$ & .09 & $.24 * *$ & $.13^{*}$ \\
\hline Manutenc. & $-.41 * *$ & $-.31 * *$ & $-.49 * *$ & $-.20 * *$ & .09 & $.13^{*}$ & .02 & $-.17 * *$ \\
\hline Compromis. & $-.50 * *$ & $-.38 * *$ & $-.66^{* *}$ & $-.31 * *$ & .02 & -.02 & $-.14 *$ & -.08 \\
\hline Coerção & $.38 * *$ & $.17 * *$ & $34 * *$ & $.11 *$ & .07 & -.03 & $.16^{* *}$ & .08 \\
\hline Igualdade & $-.44 * *$ & $-.38 * *$ & $-.62 * *$ & $-.26 * *$ & -.03 & -.01 & $-.13 *$ & -.10 \\
\hline
\end{tabular}

Nota. Parceiro - Pessoa que responde ao ERP, escala indicada acima. Respond. - pessoa a quem a variável demográfica à esquerda se refere. Confl./Amb. - Conflito/Ambivalência. Manutenc. - Manutenção. Compromis. - Compromisso.

Finalmente, há que mencionar os resultados obtidos com a escala global da RRF e com a RAS, ambas medidas globais da satisfação relacional. Os resultados para estas escalas confirmam as tendências já descritas: a Evitação apresenta uma forte correlação negativa com a satisfação, ligeiramente mais pronunciada entre as mulheres (-.75 na RRF, -.71 na RAS, ambos $p<.01)$ do que entre os homens (-.64 na RRF, -.61 na RAS, ambos $p<.01$; a diferença de correlações entre os sexos é significativa, para $p<.05$, num teste bilateral para a RRF, apenas num teste unilateral para a RAS); a Evitação de cada um dos parceiros também se repercute de forma negativa na Satisfação conjugal do outro, sendo o efeito ligeiramente mais pronunciado quando está em causa a Evitação por parte do homem (-.44 na RRF, -.42 quando se trata da RAS), do que quando se trata do efeito da Evitação da mulher (neste caso, -.36 para a RRF e -.39 para a RAS; todas estas correlações são significativamente diferentes de zero, com $p<.01$, mas não diferem significativamente entre os sexos); a Preocupação tem um efeito mínimo quando é exibida pelo homem (correlações de .04 e -.05, respectivamente para RRF e RAS, com a sua própria Satisfação, e de .03 e -..06, também respectivamente, com a da sua mulher; nenhuma destas correlações é significativa); quando se trata da Preocupação da mulher, o efeito é mais sensível, ainda que sempre muito mais fraco do que o da Evitação (correlações de -.09 e -.13, respectivamente, sendo 
a segunda significativa para $p<.05$, com a sua própria Satisfação; correlações de -.09 e -.16 , sendo a segunda significativa para $p<.01$, com a Satisfação do seu parceiro).

\section{Discussão}

Em geral, é possível concluir que, embora os resultados deste estudo tenham identificado alguns problemas em relação à estrutura factorial do ERP, a validade dos resultados das escalas é adequada. Os desajustamentos na estrutura factorial podem ter duas origens. Em primeiro lugar, a existência de uma estrutura factorial do domínio do estilo de vinculação nos adultos mais complexa do que aquela que é pressuposta pelo questionário. Mais concretamente, parece decorrer de algumas investigações anteriores que, para além dos dois factores identificados por Brennan et al. (1998) e que são de facto preponderantes nas análises deste tipo de variáveis, existem outros de menor dimensão que lhes estão subjacentes (Lafontaine \& Lussier, 2003). Esta questão deveria ser objecto de estudos adicionais, mas o problema ultrapassa os objectivos do presente artigo.

O segundo problema poderá ter a ver com diferenças entre as populações em que o questionário foi utilizado. Com efeito, o seu desenvolvimento e a selecção dos itens foram efectuados numa população de estudantes universitários Norte-Americanos, sendo por isso possível que o comportamento psicométrico dos itens seja algo diferente em populações que se distinguem não só pela sua cultura, como também pela etapa de vida e pelo tipo de relações em que estão envolvidas. Seja como for, estes aspectos não parecem ter afectado excessivamente a validade dos resultados das escalas do ERP, os quais revelaram relações teoricamente coerentes entre si e com outras medidas utilizadas neste estudo. São exemplos disto a ausência de diferenças entre sexos e de correlações significativas entre as duas escalas e entre estas e os resultados da Desiderabilidade Social, se exceptuarmos o caso da Preocupação entre as mulheres, difícil de entender e merecedora de atenção em estudos futuros.

Os resultados indicam também a presença de uma forte relação entre a vinculação evitante e a satisfação conjugal. Este resultado não pode ser tido como inteiramente esperado, uma vez que a relação entre a satisfação relacional e os diferentes estilos de vinculação insegura se tem revelado pouco consistente. Enquanto alguns estudos encontram também uma relação mais forte para o estilo evitante (e.g., Carnelley, Pietromonaco, \& Jaffe, 1994), outros encontram uma relação mais forte para o estilo preocupado (e.g., Santos et al., 2000), outros efeitos de magnitude semelhante para as duas dimensões (e.g., Levy \& Davis, 1988), ou ainda resultados diferentes nos dois sexos (e.g., Simpson, 1990). A relação entre evitação e insatisfação conjugal, no entanto, não é totalmente inesperada se pensarmos como, por exemplo, no modelo de Bartholomew (1990; Bartholomew \& Horowitz, 1991), a dimensão de evitação corresponde à representação que os indivíduos fazem dos seus parceiros relacionais (modelo do outro), enquanto que a dimensão de preocupação se relaciona com o modelo de si próprio. Não admira, por isso, que, em relações muito significativas e prolongadas, a experiência tida com o parceiro relacional acabe por ter uma influência preponderante sobre as expectativas mantidas em relação aos parceiros em geral, levando a que a relação privilegiada entre a evitação e a insatisfação surja como produto da influência da segunda sobre a primeira, e não o contrário. Apenas estudos longitudinais poderão pôr à prova esta hipótese.

Também coerente com resultados anteriores da investigação, e portanto positiva quanto à validade do questionário, é a interacção verificada com o género, que indica que a evitação tem efeitos negativos mais pronunciados quando se manifesta nos homens, acontecendo o mesmo para a preocupação quando presente nas mulheres. É de salientar, porém, a especificidade deste efeito, que apenas se verifica para as 
variáveis relatadas pelo parceiro, e não pela mesma pessoa na qual o estilo de vinculação é avaliado. Um padrão de resultados exactamente idêntico foi encontrado por Collins e Read (1990).

Finalmente, importa mencionar que os resultados para a escala de Preocupação, embora menos fortes do que os encontrados para a Evitação, são ainda assim coerentes com as expectativas teóricas. Para além da já mencionada interacção com o género, importa salientar a sua relação preferencial com as escalas que se relacionam com sentimentos de incerteza na relação (e.g., Viabilidade, Compromisso) e particularmente com o Conflito. Estes resultados fazem todo o sentido face ao significado geralmente atribuído ao factor de preocupação, que se situa precisamente dentro destes domínios de conteúdo. Ao mesmo tempo, porém, é também importante ver como outros aspectos conhecidos deste estilo de vinculação se manifestam noutros contextos, nomeadamente os aspectos do desejo intenso de intimidade e da preocupação obsessiva com o parceiro, visíveis nas correlações significativas encontradas com as escalas de Profundidade (QRI) e de Paixão (RRF).

\section{Discussão Geral}

Do que ficou dito nas secções anteriores, é possível concluir que a versão Portuguesa do ERP apresentada neste artigo é capaz de fornecer dados rigorosos e válidos em relação ao estilo de vinculação de indivíduos adultos em relação aos seus parceiros relacionais mais importantes. Essa qualidade dos dados fornecidos é tornada clara por numerosos aspectos dos resultados aqui apresentados. Em primeiro lugar, pela clareza com que a análise factorial exploratória reproduziu o modelo teórico de partida. Em segundo lugar, pelos elevados valores encontrados para os índices de consistência interna. Em terceiro lugar, pelos valores próximos de zero encontrados para as correlações entre as escalas de Evitação e de Preocupação. Em quarto lugar, pela ausência de diferenças significativas entre os resultados médios nos dois sexos. Em quinto lugar, pelas correlações baixas e não significativas com a escala de Desiderabilidade Social de Marlowe-Crowne, exceptuando uma inesperada correlação da escala de Preocupação para o sexo feminino. Este carácter inesperado da correlação encontrada, uma vez que o estilo preocupado é geralmente visto como compatível com o papel de género feminino e, portanto, como não socialmente indesejável entre as mulheres, torna o resultado ambíguo em termos do seu signficado, apontando a necessidade de mais investigações que o repliquem e eventualmente esclareçam.

Em sexto lugar, encontramos uma correlação positiva entre os estilos de vinculação dos parceiros numa relação marital, algo já encontrado em algumas investigações anteriores (Collins \& Read, 1990).

Em sétimo lugar, temos a apontar um extenso conjunto de correlações, todas elas teoricamente coerentes, entre os resultados das escalas do ERP e outras variáveis. Resumindo, constatou-se que a escala de Evitação se relaciona, em populações femininas, com uma história de vitimização por violência doméstica, bem como com uma história de IEG, sendo este último efeito anulado pela presença de uma gravidez em curso. Para além disso, a vinculação evitante nas mães constitui um preditor significativo do comportamento hiperactivo dos seus filhos no início da idade escolar, segundo o relato das próprias mães. Em relações maritais ou de tipo marital, a evitação está fortemente associada a baixos níveis de satisfação, reflectindo-se em todas as variáveis avaliadas dentro deste domínio, sem excepção.

Por seu lado, resultados elevados na escala de Preocupação relacionam-se também com a presença de uma história de IEG, entre as mulheres que não se apresentam grávidas no momento. Quanto aos seus efeitos no comportamento dos filhos em idade escolar, resultados mais elevados em Preocupação por parte das mães estão associados a maiores défices de atenção e de competências 
sociais reportados pelos professores, bem como com problemas de hiperactividade e nas competências sociais avaliados pelas próprias mães. Em termos das suas consequências para as relações de casal, a Preocupação, embora não tendo uma relação tão forte com a sua qualidade como é o caso para a Evitação, apresenta uma associação com a presença de níveis mais elevados de Conflito.

Também susceptível de ser considerado concordante com a literatura anterior é o efeito de interacção consistentemente verificado entre o estilo de vinculação e o género. Este efeito de interacção manifesta-se no facto de, quando se considera o efeito do estilo de vinculação de um indivíduo sobre as qualidades percebidas na relação marital pelo seu parceiro, se constatar que o efeito do estilo evitante é mais pronunciado quando é relatado pelo homem, enquanto que o estilo preocupado tem o seu efeito amplificado quando está presente na mulher. Vimos já como esta interacção foi também encontrada noutros estudos (Collins \& Read, 1990).

Uma ilustração adicional das diferentes implicações do estilo de vinculação em função do contexto constituído pelo papel de género são os efeitos positivos que o estilo preocupado apresenta, quando presente nos homens, sobre a sua percepção de alguns aspectos da relação. Assim, quanto mais os parceiros masculinos no Estudo 2 têm resultados elevados em Preocupação, mais vêem a relação marital como profunda e importante (acontece o inverso entre as mulheres), maior o seu nível de Paixão e mais as suas companheiras se envolvem na Manutenção da relação. Estes efeitos são facilmente compreensíveis a partir das características do estilo preocupado.

Uma vez apresentados estes aspectos, importa mencionar algumas das insuficiências dos estudos aqui incluídos, bem como pistas para estudos futuros. Entre estes avulta a falta de dados de reteste, que nos impede de avaliar o grau de estabilidade temporal dos resultados do ERP. Esta lacuna é tanto mais lamentável quando a estabilidade do estilo de vinculação foi, pelo menos a certa altura do desenvolvimento da investigação sobre este tema, objecto de alguma controvérsia (Baldwin \& Fehr, 1995; Scharfe \& Bartholomew, 1994). Actualmente, no entanto, a questão parece ter sido ultrapassada, e a maioria dos investigadores está de acordo em que a estabilidade temporal do estilo de vinculação é semelhante à da generalidade das medidas de traços de personalidade. Tal consenso não permite, no entanto, iludir a necessidade de obtenção, em estudos futuros, de dados de reteste com o ERP.

Outra limitação tem a ver com as variáveis com as quais os resultados das escalas do ERP foram correlacionados. Embora se tenha tratado de um conjunto de variáveis mais rico e diversificado do que em muitos trabalhos semelhantes, nele predominam as análises de validade convergente. Seria importante realizar mais estudos de validade discriminante, que demonstrassem que os construtos do estilo de vinculação avaliados pelo ERP não se confundem com outros, por exemplo de domínio mais geral, como sejam a auto-estima (Mikulincer, 1995) ou traços de personalidade como os do modelo do "Big Five" (John \& Srivastava, 1999).

Finalmente, parece-nos importante salientar um aspecto que, podendo ser apontado como uma lacuna no trabalho apresentado, não o é na realidade. Trata-se da verificação da possibilidade de obter, a partir dos resultados do ERP, categorias nas quais os indivíduos sejam classificados, e que correspondam à ideia tradicional dos "estilos de vinculação" como categorias de indivíduos (e.g., seguro, evitante e ansioso/ambivalente). Este objectivo é muitas vezes perseguido através do recurso a técnicas de análise classificatória, com graus de sucesso variáveis (e.g., Brennan et al., 1998). Um de nós já realizou mesmo uma análise deste tipo, com bastante sucesso (J. M. Moreira, Silva, Moleiro, Aguiar, Andrez, Bernardes, \& Afonso, 2003). A razão pela qual não realizámos este tipo de análise é conceptual, tendo a ver com dois aspectos fundamentais. Primeiro, porque a investigação tem demonstrado, inclusive recorrendo a critérios quantitativos, que o uso de categorias discretas nada acrescenta em termos de capacidade preditiva em relação àquilo que se obtém com escalas contínuas, e que nada na distribuição individual ou conjunta dos resultados dessas escalas apoia a ideia de que 
existam diferentes subpopulações homogéneas subjacentes a esses resultados (Fraley \& Waller, 1998). Segundo, porque mesmo que essas subpopulações existissem, o ERP não seria concerteza um instrumento adequado para classificar os indivíduos em grupos a elas correspondentes, dado que foi concebido para medir apenas duas dimensões, e não para reflectir as variadas combinações das diversas facetas dos estilos de vinculação, que seriam necessárias para efectuar uma classificação útil dos indivíduos. Por isso, parece-nos recomendável que o uso do ERP seja limitado àquilo para que os seus resultados se mostraram válidos: a avaliação das duas dimensões mais importantes dentro do domínio da vinculação nos adultos, nomeadamente a Evitação e a Preocupação.

\section{Apêndice A}

Questionário "Experiences in close relationships" (Brennan et al., 1998)

The following statements concern how you feel in romantic relationships. We are interested in how you generally experience relationships, not just in what is happening in a current relationship. Respond to each statement by indicating how much you agree or disagree with it. Write the number in the space provided, using the following rating scale:

\begin{tabular}{ccccccc}
\hline Disagree strongly & \multicolumn{7}{c}{ Neutral/mixed } & Agree strongly \\
\hline 1 & 2 & 3 & 4 & 5 & 6 & 7
\end{tabular}

1. I prefer not to show a partner how I feel deep down.

2. I worry about being abandoned.

3. I am very comfortable being close to romantic partners.

4. I worry a lot about my relationships.

5. Just when my partner starts to get close to me I find myself pulling away.

6. I worry that romantic partners won't care about me as much as I care about them.

7. I get uncomfortable when a romantic partner wants to be very close.

8. I worry a fair amount about losing my partner.

9. I don't feel comfortable opening up to romantic partners.

10. I often wish that my partner's feelings for me were as strong as my feelings for him/her.

11. I want to get close to my partner, but I keep pulling back.

12. I often want to merge completely with romantic partners, and this sometimes scares them away.

13. I am nervous when partners get too close to me.

14. I worry about being alone.

15. I feel comfortable sharing my private thoughts and feelings with my partner.

16. My desire to be very close sometimes scares people away.

17. I try to avoid getting too close to my partner.

18. I need a lot of reassurance that I am loved by my partner.

19. I find it relatively easy to get close to my partner.

20. Sometimes I feel that I force my partners to show more feeling, more commitment.

21. I find it difficult to allow myself to depend on romantic partners.

22. I do not often worry about being abandoned.

23. I prefer not to be too close to romantic partners.

24. If I can't get my partner to show interest in me, I get upset or angry.

25. I tell my partner just about everything.

26. I find that my partner(s) don't want to get as close as I would like.

27. I usually discuss my problems and concerns with my partner.

28. When I'm not involved in a relationship, I feel somewhat anxious and insecure.

29. I feel comfortable depending on romantic partners.

30. I get frustrated when my partner is not around as much as I would like.

31. I don't mind asking romantic partners for comfort, advice, or help.

32. I get frustrated if romantic partners are not available when I need them.

33. It helps to turn to my romantic partner in times of need.

34. When romantic partners disapprove of me, I feel really bad about myself.

35. I turn to my partner for many things, including comfort and reassurance.

36. I resent it when my partner spends time away from me. 


\section{Apêndice B}

\section{Questionário "Experiências em Relações Próximas" (Versão Masculina)}

Instruções: Por favor, leia cada uma das seguintes afirmações e avalie o grau em que cada uma delas descreve os seus sentimentos acerca das relações com as suas parceiras (p. ex., mulher, namorada, companheira, etc). Pense em todas as suas relações, passadas e presentes, e responda em termos de como geralmente se sente nessas relações. Responda a cada afirmação indicando o quanto concorda ou discorda. Assinale com um círculo o número correspondente à sua resposta, utilizando a seguinte escala:

\begin{tabular}{ll}
\hline Discordo fortemente & \multicolumn{1}{c}{ Neutro/misto } \\
\hline 1. & Prefiro não mostrar à minha parceira como me sinto lá no fundo. \\
2. Preocupa-me o ser abandonado. \\
3. Sinto-me muito confortável em estar próximo das minhas parceiras. \\
4. Preocupo-me muito com as minhas relações afectivas. \\
5. Quando a minha parceira começa a aproximar-se emocionalmente de mim, \\
tendo a afastar-me.
\end{tabular}

6. Preocupa-me que as minhas parceiras não se preocupem tanto comigo como eu com elas.

7. Sinto-me desconfortável quando uma parceira quer ser muito próxima.

8. Preocupo-me bastante com a possibilidade de perder a minha parceira.

9. Não me sinto confortável ao "abrir-me" com as minhas parceiras.

10. Desejo muitas vezes que os sentimentos da minha parceira por mim sejam tão fortes como os meus por ela.

11. Quero tornar-me próximo da minha parceira mas estou sempre a afastar-me.

12. Quero muitas vezes unir-me completamente às minhas parceiras e isso, por vezes, afasta-as.

13. Fico nervoso quando as minhas parceiras se tornam demasiado próximas.

14. Preocupa-me o estar sozinho.

15. Sinto-me confortável ao partilhar os meus pensamentos e sentimentos íntimos com a minha parceira

16. O meu desejo de me tornar muito próximo por vezes assusta as pessoas.

17. Tento evitar tornar-me demasiado próximo da minha parceira.

18. Preciso de muitas manifestações de amor para me sentir amado pela minha parceira.

19. Sinto que é relativamente fácil tornar-me próximo da minha parceira.

20. Às vezes sinto que pressiono as minhas parceiras para mostrarem mais sentimento e mais empenho.

21. Sinto dificuldade em permitir a mim mesmo apoiar-me nas minhas parceiras.

22. Não me preocupo muitas vezes com o ser abandonado.

23. Prefiro não ser muito próximo das minhas parceiras.

24. Se não consigo que a minha parceira mostre interesse por mim, fico perturbado ou zangado.

25. Conto praticamente tudo à minha parceira.

26. Penso que a minha parceira não se quer tornar tão próxima como eu gostaria.

27. Costumo discutir os meus problemas e preocupações com a minha parceira.

28. Quando não estou envolvido numa relação, sinto-me um pouco ansioso e inseguro.

29. Sinto-me confortável ao apoiar-me nas minhas parceiras.

30. Fico frustrado quando a minha parceira não está comigo tanto tempo como eu gostaria.

31. Não me importo de pedir às minhas parceiras conforto, conselhos ou ajuda.

32. Fico frustrado se as minhas parceiras não estão disponíveis quando eu preciso delas.

33. Ajuda-me poder contar com a minha parceira nas situações de necessidade.

34. Quando as minhas parceiras me desaprovam, sinto-me muito mal comigo mesmo.

35. Recorro à minha parceira para muitas coisas, incluindo conforto e segurança.

36. Fico ressentido quando a minha parceira passa tempo longe de mim.

\begin{tabular}{|c|c|c|c|c|c|c|}
\hline & & & & \multicolumn{3}{|c|}{ Concordo fortemente } \\
\hline 5 & & 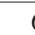 & & & 7 & \\
\hline 1 & 2 & 3 & 4 & 5 & 6 & 7 \\
\hline 1 & 2 & 3 & 4 & 5 & 6 & 7 \\
\hline 1 & 2 & 3 & 4 & 5 & 6 & 7 \\
\hline 1 & 2 & 3 & 4 & 5 & 6 & 7 \\
\hline 1 & 2 & 3 & 4 & 5 & 6 & 7 \\
\hline 1 & 2 & 3 & 4 & 5 & 6 & 7 \\
\hline 1 & 2 & 3 & 4 & 5 & 6 & 7 \\
\hline 1 & 2 & 3 & 4 & 5 & 6 & 7 \\
\hline 1 & 2 & 3 & 4 & 5 & 6 & 7 \\
\hline 1 & 2 & 3 & 4 & 5 & 6 & 7 \\
\hline 1 & 2 & 3 & 4 & 5 & 6 & 7 \\
\hline 1 & 2 & 3 & 4 & 5 & 6 & 7 \\
\hline 1 & 2 & 3 & 4 & 5 & 6 & 7 \\
\hline 1 & 2 & 3 & 4 & 5 & 6 & 7 \\
\hline 1 & 2 & 3 & 4 & 5 & 6 & 7 \\
\hline 1 & 2 & 3 & 4 & 5 & 6 & 7 \\
\hline 1 & 2 & 3 & 4 & 5 & 6 & 7 \\
\hline 1 & 2 & 3 & 4 & 5 & 6 & 7 \\
\hline 1 & 2 & 3 & 4 & 5 & 6 & 7 \\
\hline 1 & 2 & 3 & 4 & 5 & 6 & 7 \\
\hline 1 & 2 & 3 & 4 & 5 & 6 & 7 \\
\hline 1 & 2 & 3 & 4 & 5 & 6 & 7 \\
\hline 1 & 2 & 3 & 4 & 5 & 6 & 7 \\
\hline 1 & 2 & 3 & 4 & 5 & 6 & 7 \\
\hline 1 & 2 & 3 & 4 & 5 & 6 & 7 \\
\hline 1 & 2 & 3 & 4 & 5 & 6 & 7 \\
\hline 1 & 2 & 3 & 4 & 5 & 6 & 7 \\
\hline 1 & 2 & 3 & 4 & 5 & 6 & 7 \\
\hline 1 & 2 & 3 & 4 & 5 & 6 & 7 \\
\hline 1 & 2 & 3 & 4 & 5 & 6 & 7 \\
\hline 1 & 2 & 3 & 4 & 5 & 6 & 7 \\
\hline 1 & 2 & 3 & 4 & 5 & 6 & 7 \\
\hline 1 & 2 & 3 & 4 & 5 & 6 & 7 \\
\hline 1 & 2 & 3 & 4 & 5 & 6 & 7 \\
\hline 1 & 2 & 3 & 4 & 5 & 6 & 7 \\
\hline 1 & 2 & 3 & 4 & 5 & 6 & 7 \\
\hline
\end{tabular}




\section{Apêndice C}

\section{Questionário "Experiências em Relações Próximas" (Versão Feminina)}

Instruções: Por favor, leia cada uma das seguintes afirmações e avalie o grau em que cada uma delas descreve os seus sentimentos acerca das relações com os seus parceiros (p. ex., marido, namorado, companheiro, etc). Pense em todas as suas relações, passadas e presentes, e responda em termos de como geralmente se sente nessas relações. Responda a cada afirmação indicando o quanto concorda ou discorda. Assinale com um círculo o número correspondente à sua resposta, utilizando a seguinte escala:

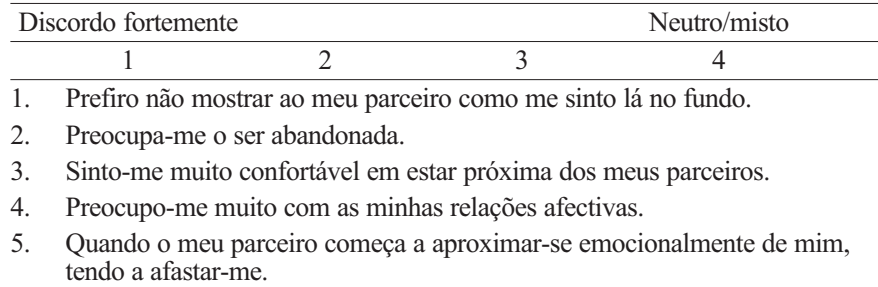

6. Preocupa-me que os meus parceiros não se preocupem tanto comigo como eu com eles.

7. Sinto-me desconfortável quando um parceiro quer ser muito próximo.

8. Preocupo-me bastante com a possibilidade de perder o meu parceiro.

9. Não me sinto confortável ao "abrir-me" com os meus parceiros.

10. Desejo muitas vezes que os sentimentos do meu parceiro por mim sejam tão fortes como os meus por ele.

11. Quero tornar-me próxima do meu parceiro mas estou sempre a afastar-me.

12. Quero muitas vezes unir-me completamente aos meus parceiros e isso, por vezes, afasta-os.

13. Fico nervosa quando os meus parceiros se tornam demasiado próximos.

14. Preocupa-me o estar sozinha.

15. Sinto-me confortável ao partilhar os meus pensamentos e sentimentos íntimos com o meu parceiro

16. O meu desejo de me tornar muito próxima por vezes, assusta as pessoas.

17. Tento evitar tornar-me demasiado próxima do meu parceiro.

18. Preciso de muitas manifestações de amor para me sentir amada pelo meu parceiro.

19. Sinto que é relativamente fácil tornar-me próxima do meu parceiro.

20. Às vezes sinto que pressiono os meus parceiros para mostrarem mais sentimento e mais empenho.

21. Sinto dificuldade em permitir a mim mesma apoiar-me nos meus parceiros.

22. Não me preocupo muitas vezes com o ser abandonada.

23. Prefiro não ser muito próxima dos meus parceiros.

24. Se não consigo que o meu parceiro mostre interesse por mim, fico perturbada ou zangada.

25. Conto praticamente tudo ao meu parceiro.

26. Penso que o meu parceiro não se quer tornar tão próximo como eu gostaria.

27. Costumo discutir os meus problemas e preocupações com o meu parceiro.

28. Quando não estou envolvida numa relação, sinto-me um pouco ansiosa e insegura.

29. Sinto-me confortável ao apoiar-me nos meus parceiros.

30. Fico frustrada quando o meu parceiro não está comigo tanto tempo como eu gostaria.

31. Não me importo de pedir aos meus parceiros conforto, conselhos ou ajuda.

32. Fico frustrada se os meus parceiros não estão disponíveis quando eu preciso deles.

33. Ajuda-me poder contar com o meu parceiro nas situações de necessidade.

34. Quando os meus parceiros me desaprovam, sinto-me muito mal comigo mesma.

35. Recorro ao meu parceiro para muitas coisas, incluindo conforto e segurança

36. Fico ressentida quando o meu parceiro passa tempo longe de mim.

\begin{tabular}{|c|c|c|c|c|c|c|}
\hline & & & \multicolumn{4}{|c|}{ Concordo fortemente } \\
\hline 5 & \multicolumn{3}{|c|}{6} & \multicolumn{3}{|c|}{7} \\
\hline 1 & 2 & 3 & 4 & 5 & 6 & 7 \\
\hline 1 & 2 & 3 & 4 & 5 & 6 & 7 \\
\hline 1 & 2 & 3 & 4 & 5 & 6 & 7 \\
\hline 1 & 2 & 3 & 4 & 5 & 6 & 7 \\
\hline 1 & 2 & 3 & 4 & 5 & 6 & 7 \\
\hline 1 & 2 & 3 & 4 & 5 & 6 & 7 \\
\hline 1 & 2 & 3 & 4 & 5 & 6 & 7 \\
\hline 1 & 2 & 3 & 4 & 5 & 6 & 7 \\
\hline 1 & 2 & 3 & 4 & 5 & 6 & 7 \\
\hline 1 & 2 & 3 & 4 & 5 & 6 & 7 \\
\hline 1 & 2 & 3 & 4 & 5 & 6 & 7 \\
\hline 1 & 2 & 3 & 4 & 5 & 6 & 7 \\
\hline 1 & 2 & 3 & 4 & 5 & 6 & 7 \\
\hline 1 & 2 & 3 & 4 & 5 & 6 & 7 \\
\hline 1 & 2 & 3 & 4 & 5 & 6 & 7 \\
\hline 1 & 2 & 3 & 4 & 5 & 6 & 7 \\
\hline 1 & 2 & 3 & 4 & 5 & 6 & 7 \\
\hline 1 & 2 & 3 & 4 & 5 & 6 & 7 \\
\hline 1 & 2 & 3 & 4 & 5 & 6 & 7 \\
\hline 1 & 2 & 3 & 4 & 5 & 6 & 7 \\
\hline 1 & 2 & 3 & 4 & 5 & 6 & 7 \\
\hline 1 & 2 & 3 & 4 & 5 & 6 & 7 \\
\hline 1 & 2 & 3 & 4 & 5 & 6 & 7 \\
\hline 1 & 2 & 3 & 4 & 5 & 6 & 7 \\
\hline 1 & 2 & 3 & 4 & 5 & 6 & 7 \\
\hline 1 & 2 & 3 & 4 & 5 & 6 & 7 \\
\hline 1 & 2 & 3 & 4 & 5 & 6 & 7 \\
\hline 1 & 2 & 3 & 4 & 5 & 6 & 7 \\
\hline 1 & 2 & 3 & 4 & 5 & 6 & 7 \\
\hline 1 & 2 & 3 & 4 & 5 & 6 & 7 \\
\hline 1 & 2 & 3 & 4 & 5 & 6 & 7 \\
\hline 1 & 2 & 3 & 4 & 5 & 6 & 7 \\
\hline 1 & 2 & 3 & 4 & 5 & 6 & 7 \\
\hline 1 & 2 & 3 & 4 & 5 & 6 & 7 \\
\hline 1 & 2 & 3 & 4 & 5 & 6 & 7 \\
\hline 1 & 2 & 3 & 4 & 5 & 6 & 7 \\
\hline
\end{tabular}




\section{Referências}

Ainsworth, M. D. S., Blehar, M. C., Waters, E., \& Wall, S. (1978). Patterns of attachment: A psychological study of the strange situation. Hillsdale, NJ: Lawrence Erlbaum.

Anisfeld, E., Casper, V., Nozyee, M., \& Cunningham, N. (1990). Does infant carrying promote attachment? An experimental study of the effects of increased physical contact on the development of attachment [Versão electrónica]. Child Development, 61, 1617-1627.

Baldwin, M. W., \& Fehr, B. (1995). On the instability of attachment style ratings. Personal Relationships, 2, 247-261.

Bartholomew, K. (1990). Avoidance of intimacy: An attachment perspective. Journal of Social and Personal Relationships, 7, 147-178.

Bartholomew, K., \& Horowitz, L. M. (1991). Attachment styles among young adults: A test of a fourcategory model. Journal of Personality and Social Psychology, 61, 226-244.

Bowlby, J. (1976). A natureza da ligação da criança com a mãe. In L. Soczka (Ed.), As ligações infantis (pp. 105-153). Amadora: Bertrand. (Trabalho original publicado em 1958)

Bowlby, J. (1969). Attachment and loss: Vol. 1. Attachment. London: Hogarth Press.

Bowlby, J. (1973). Attachment and loss: Vol. 2. Separation, anxiety and anger. London: Hogarth Press.

Bowlby, J. (1979). The making and breaking of affectional bonds. London: Routledge.

Bowlby, J. (1980). Attachment and loss: Vol. 3. Loss, sadness and depression. London: Hogarth Press.

Bowlby, J. (1988). A secure base: Clinical applications of attachment theory. New York: Basic Books.

Brennan, K. A., Clark, C. L., \& Shaver, P. R. (1998). Self-report measurement of adult romantic attachment: An integrative overview. In J. A. Simpson \& W. S. Rholes (Eds.), Attachment theory and close relationships (pp. 46-76). New York: Guilford.

Carnelley, K. B., Pietromonaco, P. R., \& Jaffe, K. (1994). Depression, working models of others, and relationship functioning. Journal of Personality and Social Psychology, 66, 127-140.

Cassidy, J., \& Shaver, P. R. (Eds.). (1999). Handbook of attachment: Theory, research, and clinical applications. New York: Guilford.

Collins, N. L., \& Read, S. J. (1990). Adult attachment, working models, and relationship quality in dating couples. Journal of Personality and Social Psychology, 58, 644-663.

Crowell, J. A., Treboux, D., \& Waters, E. (1999). The Adult Attachment Interview and the Relationship Questionnaire: Relations to reports of mothers and partners. Personal Relationships, 6, 1-18.

Davis, K. E., \& Latty-Mann, H. (1987). Lovestyles and relationship quality: A contribution to validation. Journal of Social and Personal Relationships, 4, 409-428.

Fleming, A. S., Ruble, D., Krieger, H., \& Wong, P. Y. (1997). Hormonal and experiential correlates of maternal responsiveness during pregnancy and the puerperium in human mothers [Versão electrónica]. Hormones and Behavior, 31, 145-158.

Fraley, R. C., \& Waller, N. G. (1998). Adult attachment patterns: A test of the typological model. In J. A. Simpson \& W. S. Rholes (Eds.), Attachment theory and close relationships (pp. 77-114). New York: Guilford.

Fraley, R. C., Waller, N. G., \& Brennan, K. A. (2000). An item response theory analysis of self-report measures of adult attachment. Journal of Personality and Social Psychology, 78, 350-365. 
Gomes, M. J. (2001). Estilos de vinculação materna e comportamento social da criança no período de integração na escola. Dissertação de Mestrado em Psicologia, Faculdade de Psicologia e de Ciências da Educação, Universidade de Lisboa.

Griffin, D., \& Bartholomew, K. (1994a). Models of self and other: Fundamental dimensions underlying measures of adult attachment. Journal of Personality and Social Psychology, 67, 430-445.

Griffin, D. W., \& Bartholomew, K. (1994b). The metaphysics of measurement: The case of adult attachment. In K. Bartholomew \& D. Perlman (Eds.), Advances in personal relationships: Vol. 5. Attachment processes in adulthood (pp. 17-52). London: Jessica Kingsley.

Hazan, C., \& Shaver, P. (1987). Romantic love conceptualized as an attachment process. Journal of Personality and Social Psychology, 52, 511-524.

Hendrick, C., \& Hendrick, S. S. (1989). Research on love: Does it measure up? Journal of Personality and Social Psychology, 56, 784-794.

Hendrick, S. S. (1988). A generic measure of relationship satisfaction. Journal of Marriage and the Family, 50, 93-98.

Hendrick, S. S., Dicke, A., \& Hendrick, C. (1998). The Relationship Assessment Scale. Journal of Social and Personal Relationships, 15, 137-142.

Hesse, E. (1999). The Adult Attachment Interview: Historical and current perspectives. In J. Cassidy \& P. R. Shaver (Eds.), Handbook of attachment: Theory, research, and clinical applications (pp. 395-433). New York: Guilford.

Jerome, E. M., \& Liss, M. (2005). Relationships between sensory processing style, adult attachment, and coping [Versão electrónica]. Personality and Individual Differences, 38, 1341-1352.

John, O. P., \& Srivastava, S. (1999). The Big Five trait taxonomy: History, measurement, and theoretical perspectives. In L. A. Pervin \& O. P. John (Eds.), Handbook of personality: Theory and research (pp. 102-138). New York: Guilford.

Lafontaine, M.-F., \& Lussier, Y. (2003). Structure bidimensionnelle de l'attachement amoureux: Anxiété face à l'abandon et évitement de l'intimité [Versão electrónica]. Canadian Journal of Behavioural Science, 35, 56-60.

Levy, M. B., \& Davis, K. E. (1988). Lovestyles and attachment styles compared: Their relations to each other and to various relationship characteristics. Journal of Social and Personal Relationships, 5, 439-471.

Main, M., \& Weston, D. R. (1982). Avoidance of the attachment figure in infancy: Descriptions and interpretations. In C. M. Parkes \& J. Stevenson-Hinde (Eds.), The place of attachment in human behavior (pp. 31-59). New York: Basic Books.

Mallinckrodt, B., Porter, M. J., \& Kivlighan, D. M. (2005). Client attachment to therapist, depth of insession exploration, and object relations in brief psychotherapy [Versão electrónica]. Psychotherapy: Theory, Research, Practice, Training, 42, 85-100.

Mallinckrodt, B., \& Wang, C. C. (2004). Quantitative methods for verifying semantic equivalence of translated research instruments: A Chinese version of the Experiences in Close Relationships scale [Versão electrónica]. Journal of Counseling Psychology, 51, 368-379.

Mikulincer, M. (1995). Attachment style and the mental representation of the self. Journal of Personality and Social Psychology, 69, 1203-1215.

Mikulincer, M., \& Florian, V. (2000). Exploring individual differences in reactions to mortality salience: Does attachment style regulate terror management mechanisms? Journal of Personality and Social Psychology, 79, 260-273. 
Mikulincer, M., Florian, V., \& Tolmacz, R. (1990). Attachment styles and fear of personal death: A case study of affect regulation. Journal of Personality and Social Psychology, 58, 273-280.

Moreira, A. R. (2001). Vinculação em mulheres com história de interrupção espontânea da gravidez: Estudo exploratório. Dissertação de Mestrado em Psicologia, Faculdade de Psicologia e de Ciências da Educação, Universidade de Lisboa.

Moreira, J. M., Bernardes, S., Andrez, M., Aguiar, P., Moleiro, C., \& Silva, M. F. (1998). Social competence, personality and adult attachment style in a Portuguese sample. Personality and Individual Differences, 24, 565-570.

Moreira, J. M., Silva, M. F., Moleiro, C., Aguiar, P., Andrez, M., Bernardes, S., \& Afonso, H. (2003). Social support as an offshoot of attachment style. Personality and Individual Differences, 34, 485-501.

Moss, E., St-Laurent, D., Rousseau, D., Parent, S., Gosselin, C., \& Saintonge, J. (1999). L'attachement à l'âge scolaire et le développement des troubles de comportement [Versão electrónica]. Revue Canadienne des Sciences du Comportement, 31, 107-118.

Obegi, J. H., Morrison, T. L., \& Shaver, P. R. (2004). Exploring intergenerational transmission of attachment style in young female adults and their mothers. Journal of Social and Personal Relationships, 21, 625-638.

Oliveira, A. P., Filipe, L. A., \& Faustino, M. (2000). Violência doméstica: Influência dos estilos de vinculação e dos comportamentos interpessoais. Trabalho realizado no âmbito da disciplina de Investigação em Psicologia Clínica da licenciatura em Psicologia, Faculdade de Psicologia e de Ciências da Educação da Universidade de Lisboa.

Pierce, G. R., Sarason, I. G., Sarason, B. R., Solky-Butzel, J. A., \& Nagle, L. C. (1997). Assessing the quality of personal relationships. Journal of Social and Personal Relationships, 14, 339-356.

Santos, M. J., Feijão, M. T., \& Mesquita, R. (2000). Relações entre estilos de vinculação, estilos de resolução de conflito e satisfação nas relações amorosas em mulheres com um relacionamento heterossexual. Manuscrito não publicado, Faculdade de Psicologia e de Ciências da Educação, Universidade de Lisboa.

Scharfe, E., \& Bartholomew, K. (1994). Reliability and stability of adult attachment patterns. Personal Relationships, 1, 23-43.

Shaver, P., Hazan, C., \& Bradshaw, D. (1988). Love as attachment: The integration of three behavioral systems. In R. J. Sternberg \& M. L. Barnes (Eds.), The psychology of love (pp. 68-99). New Haven, CT: Yale University Press.

Simpson, J. A. (1990). Influence of attachment styles on romantic relationships. Journal of Personality and Social Psychology, 59, 971-980.

Ullmann, R. K, Sleator, E. K., Sprague, R. L., \& MetriTech Staff. (1997). ACTeRS teacher and parent forms manual (2nd ed.). Champaign, IL: MetriTech.

van IJzendoorn, M. H. (1995). Adult attachment representations, parental responsiveness, and infant attachment: A meta-analysis on the predictive validity of the Adult Attachment Interview. Psychological Bulletin, 117, 387-403.

Weinfield, N. S., Sroufe, L. A., Egeland, B., \& Carlson, E. A. (1999). The nature of individual differences in infant-caregiver attachment. In J. Cassidy \& P. R. Shaver (Eds.), Handbook of attachment (pp. 68-88). New York: Guilford. 